\title{
Relocation stress and nursing implications
}

Lorna Kwai Ping Suen RN, RM, BN, MPH, PhD, Associate Professor, The Nethersole School of Nursing, The Chinese University of Hong Kong, Hong Kong

Tina Wing Yan Lee RN, BN, MN, Registered Nurse, Prince of Wales Hospital, Hong Kong

Jackson Chi Ho Yeung RN, Registered Nurse, Queen Mary Hospital, Hong Kong

Key Words: critical care intensive care unit $\quad$ nursing $\quad$ relocation stress

E-mail: lornasuen@cuhk.edu.hk

\section{ESPAÑOL}

Estrés por traslado e implicancia para enfermería

Palabras clave

Cuidado crítico, enfermería, estrés por traslado, unidad de cuidado intensivo,

Resumen

- El traslado inoportuno así como los factores ambientales, del personal, y del cliente pueden contribuir al estrés debido al traslado del paciente de $\mathrm{UCl}$.

- El estrés por el traslado puede causar efectos negativos en el bienestar psicológico y la recuperación física del paciente. Una mejor preparación para el cambio, establecer políticas sobre traslados, fortalecer la formación del plantel y el uso de enfermería de vinculación se recomiendan para disminuir el estrés.

\section{SUMMARY}

- Untimely transfer, as well as environmental, staffing, and client factors may contribute to relocation stress of ICU patients.

- Translocation stress may pose negative effects on the psychological well-being and physical recovery of patients.

- Better transfer preparation, set-up policies on transfer, strengthened staff training, and the use of liaison nurse are recommended to lessen relocation stress.

\section{INTRODUCTION}

"I was woken up at three o'clock in the morning, and in 15 minutes was transferred from the intensive care unit to another room. The doctors said an emergency case needed the bed more than I do," said Mr T (name changed to protect patient identity), an 84 year-old patient who was admitted to the ICU last month to have his poor respiratory condition managed. He was transferred to a surgical general ward at midnight. "They made it seem like I was a patient with no feelings, being thrown around like a ball!"

Admission to the ICU is typically perceived as a troubling experience for patients and their relatives, resulting in distress and negative life changes. On the contrary, transferring from the intensive care unit
(ICU) is commonly viewed as a positive event, as this is a sign that the condition of the patient has stabilised. However, transfer can also be more distressing for patients and their relatives as compared to ICU admission (Beard, 2005; Coyle, 2001). In ICUs where the focus is mainly on life and survival, discharge issues might sometimes be overlooked. To maintain the quality of care across the wellness continuum, healthcare professionals should therefore analyse current ICU management standards and take proactive measures to prevent the adverse outcomes brought forth by poorly managed ICU discharge.

Similar to the aforementioned case, the loss of close monitoring, secure environment, and dedicated staff when transferring from the ICU causes anxiety. This condition is referred to as "transfer anxiety" (Bouley et al., 1994; Jenkins \& Rogers, 1995) or "relocation stress" (Manion \& Rantz, 1995; Carpenito, 2000). Relocation stress was defined by Carpenito (2000, p. 175) as "a state in which an individual experiences physiological and/or psychosocial disturbances as a result of transfer from one environment to another." In a qualitative study by Field et al. (2008), the participants described the experience of being transferred from the ICU as a "complete shock," "awful," or "distressing."

The physiological responses to stress include irregular or increased heart rate, altered blood pressure or respiration, and sleep disturbance (McKinney \& Melby, 2002; Field et al., 2008). Smith (1976) reported that 70 percent of patients being transferred from the intensive coronary care unit experience increased catecholamine excretion and complications in the cardiovascular system. For psychological consequences, Chaboyer et al. (2005) reframed the perceptions of patients and their families on being transferred from the ICU into four categories: sudden abandonment, vulnerability, unimportance, and ambivalence. Emotions can be further described as those of insecurity, rejection, fear, anger, confusion or tension (Choate \& Stewart, 2002; Chaboyer et al., 2005). Burden would also be added to frontline staff with the possible occurrence of mistrust, withdrawal, and uncooperativeness, especially if the needs of patients and/or their families are not appropriately addressed. As a result, a higher risk of mortality or increased unplanned patient readmission due to relocation stress might occur (Chaboyer \& Elliott, 2007).

\section{CONTRIBUTING FACTORS}

The following factors may contribute to relocation stress as patients are transferred from the ICU.

\section{Untimely transfer}

Many ICU transfer cases are not well prepared. Surprisingly, decisions to transfer are not purely based on the patient's physical status but also on the need for an ICU bed. From time to time, this abrupt transition would happen at night, creating more anxiety as 
compared to daytime transfer (McKinney \& Melby, 2002). Therefore, an untimely discharge from the ICU exacerbates feelings of being abandoned. A hurried transfer also reduces the time for patients to psychologically prepare themselves for the busy atmosphere in the general ward.

\section{Environmental factors}

Patients experience tremendous environmental change upon transition from the ICU to the general ward. Patients in the ICU are monitored with high-technology machines, and the nurse-to-patient ratio is $1: 1$. In a general ward, however, there is a huge change in the level of care, as the availability of healthcare workers and monitoring machines in general settings is reduced (McKinney \& Melby, 2002; Chaboyer et al., 2005). In the ICU, patients may be surrounded by numerous machines such as fluid infusion pumps, drip stands, ventilators, and portable haemodialysers. Given this, patients lose their sense of security established in a protective environment once they are transferred to the general ward (Coyle, 2001; McKinney \& Melby, 2002). Feelings of security are also diminished by the crowded and noisy environment in general wards (Field et al., 2008). Aside from physical adjustments, administrative-level changes such as in the pattern and length of visiting hours also create negative experiences. Once a patient has been transferred from the ICU, the abrupt change in environment can be a stressor.

\section{Staffing factors}

Communication problem has been reported to be the main difficulty faced by ward nurses. They perceive ICU nurses as possessing no empathy, always endeavouring to speed up a transition and exerting immense pressure on ward nurses. Communication breakdown thus occurs at rushed handover or in disorganised case notes (Whittaker \& Ball, 2000). At times, documents are poorly prepared before transfer, and organising and studying case notes are also time consuming, thus impeding patient assessment and care. Further, with an increasing nurse-to-patient ratio, wards are always understaffed, with ward nurses given heavy workloads. Nurses are therefore more likely to give up time for psychological care when they feel stressed (McElligot, 2003).

\section{Client factors}

The personal factors of patients and their family members may also affect the response to the transfer. These factors include their own coping mechanisms, past experience, or previous perception regarding the hospital environment, and perception and expectation regarding patient illness and progress. The perceived negative feelings of the patients' families might sometimes be stronger than those of the patients themselves (Chaboyer et al., 2005). Although they appreciate the transition from a critical setting to a less traumatising environment, they would usually doubt whether this transfer is really best for the patient. Further, many patients and their relatives do not perceive the transfer time as accurate. They expect intensive care to continue as they are still in a critical state (Coyle, 2001).

\section{NURSING IMPLICATIONS}

\section{Transfer preparation}

To carry out a smooth transfer, critical care nurses should sufficiently prepare the patients. Early planning allows for a buffering period for gradual change, resulting in less stress. Agreeing on a date of transfer could be beneficial (Coyle, 2001). A pre-transfer visit from the receiving ward nurse and a post-transfer follow-up from the clinical nurse specialist are also recommended (Hall-Smith et al., 1997; Wesson, 1997; Coyle, 2001; McKinney \& Melby, 2002). Equally beneficial are pamphlets containing information on the transfer plan, ward facts, staffing, expectations in general wards, support services for family members, visiting hours, and nurse-topatient ratio of the receiving wards. Apart from written information, videos introducing the patient's journey in the ICU as well as the discharge process, general ward environment, and ward routines could be shown to family members in waiting areas. Involving the family in the assessment and intervention is very important to gain cooperation. Information on treatment and care plans should likewise be introduced to the patient and his or her family.

Prior to the transfer, critical care nurses can provide patients with positive progression reports regarding their health conditions (McKinney \& Melby, 2002). If allowed, the amount of monitoring and supporting equipment can be reduced, along with a reassurance of improvement. Consequently, relocation stress is minimised as patients are able to gradually cope with the perceived loss of adequate support and transfer changes (Saarmann, 1993; Jenkins \& Rogers, 1995).

\section{Set-up policies on transfer and strengthen staff training}

Policies should be clearly established on when to transfer a case from the ICU, such as avoiding nighttime or premature transfer if possible. ICU nurses should be encouraged to project the transition as a positive event to the patients and their families (Choate \& Stewart, 2002; McKinney \& Melby, 2002). They should always be conscious of translocation stress and be aware of the benefits of discharge preparation to the patients and their families (Coyle, 2001). Early or daytime transfer with the presence of a family member is preferable (Boutilier, 2007).

For familiarisation with current ward situations, a nurse exchange program between the ICU and general ward staff could be considered. Working in harmony will facilitate care provision and consistency. Further, continuous education is always essential to professional nursing. General ward nurses should be constantly educated, so they will be more sensitive to the emotional aspects associated with ICU discharge.

Discharge documents prepared in the ICU should also be clear, comprehensive, relevant, and concise to facilitate the handover process to the general wards. On the other hand, intermediate care settings and high dependency units are becoming more popular in hospitals. ICU patients have become accustomed to these settings, a fact that may be considered before the transfer to general wards. As the nurse-to-patient ratio in a general ward is usually lower, more nursing resources could be provided in these units.

\section{Liaison nurse}

An ICU liaison nurse plays an important role in linking the ICU and general wards, assessing any health risk after discharge from the ICU, and providing support and clarifying care issues to the ward staff (Chaboyer \& Elliott, 2007). The use of a liaison nurse in certain institutions for resolving transfer stress and maintaining continuity of care (for example, post-transfer follow-up) is encouraged in order to ease the translocation process (Chaboyer, 2004; Boutilier, 2007).

\section{CONCLUSIONS}

Both admission and discharge from the intensive care unit can be traumatic to patients and their families, resulting in stress and anxiety. Translocation stress is becoming increasingly prevalent, and it poses negative effects on the psychological well-being and physical recovery of patients. The literature has suggested a number of factors that contribute to relocation stress, including untimely transfer, as well as environmental, staffing, and client factors. Therefore, health care 
professionals should always be aware of relocation stress and take precautions to prevent it. Early planning and transfer preparation that involves family members, supplementary information through written materials, establishment of appropriate policies for patient transfer, provision of more staff training, and the use of liaison nurses are recommended to lessen relocation stress. A holistic plan for transfer will ensure smooth transition and prevent any adverse effects caused by poorly prepared ICU discharge.

\section{REFERENCES}

Ball C, McElligot M (2003). Realising the potential of critical care nurses: an exploratory study of the factors that affect and comprise the nursing contribution to the recovery of critically ill patients. Intensive and Critical Care Nursing 19 (4), 226-238.

Beard H (2005). Does intermediate care minimize relocation stress for patients leaving the ICU? Nursing in Critical Care 10 (6), 272278.

Bouley G, von Hofe K, Blatt L (1994). Holistic care of the critically ill: meeting both patient and family needs. Dimensions of Critical Care Nursing 13 (4), 218-223.

Boutilier S (2007). Leaving critical care: facilitating a smooth transition. Dimensions of Critical Care Nursing 26 (4), 137-142.

Carpenito-Moyet LJ (2000). Nursing Diagnosis: Application to Clinical Practice (8th ed.). Philadelphia: Lippincott, Williams and Wilkins.

Chaboyer W, Foster MM, Foster M, Kendall E (2004). The Intensive Care Unit liaison nurse: towards a clear role description. Intensive Critical Care Nursing 20 (2), 77-86.

Chaboyer W, Elliott D (2007). Care across the continuum. In: Elliott D, Aitken L, Chaboyer W (eds.). ACCCN's Critical Care Nursing. Sydney: Mosby Elsevier.
Chaboyer W, Kendall E, Kendall M, Foster M (2005). Transfer out of intensive care: a qualitative exploration of patient and family perceptions. Australian Critical Care 18 (4), 138-145.

Choate K, Stewart M (2002). Reducing anxiety in patients and families discharged from ICU. Australian Nursing Journal 10 (5), 29.

Coyle MA (2001). Transfer anxiety: preparing to leave intensive care. Intensive and Critical Care Nursing 17 (3), 138-143.

Field K, Prinjha S, Rowan K (2008). One patient amongst many: a qualitative analysis of intensive care unit patients' experiences of transferring to the general ward. Critical Care 12 (1), R21.

Jenkins DA, Rogers M (1995). Transfer anxiety in patients with myocardial infarction. British Journal of Nursing 4 (21), 12481252.

Hall-Smith J, Ball C, Coakley J (1997). Follow-up services and the development of a clinical nurse specialist in intensive care. Intensive and Critical Care Nursing 13 (5), 243-248.

McKinney AA, Melby V (2002). Relocation stress in critical care: a review of the literature. Journal of Clinical Nursing 11 (2), 149157.

Saarmann L (1993). Transfer out of critical care: freedom or fear? Critical Care Nursing Quarterly 16 (1), 78-85.

Smith MC (1976). Patient responses to being transferred during hospitalization. Nursing Research 25 (3), 192-196.

Wesson JS (1997). Meeting the informational, psychosocial and emotional needs of each ICU patient and family. Intensive and Critical Care Nursing 13 (2), 111-118.

Whittaker J, Ball C. (2000). Discharge from intensive care: a view from the ward. Intensive and Critical Care Nursing 16 (3), 135143. 